\title{
Penerapan Metode Klasifikasi ABC dan 5S Pada Gudang Tools PT. Mesin Isuzu Indonesia
}

\author{
Olga Aditya Putra ${ }^{*}$ dan Indro Prakoso² \\ 1,2 Program Studi Teknik Industri, Fakultas Teknik, Universitas Jenderal Soedirman \\ Jl. Mayjend Sungkono KM5, Blater, Kalimanah, Purbalingga 53371 \\ *email: adityaolga99@gmail.com
}

\begin{abstract}
PT.Mesin Isuzu Indonesia manufacturing industry engaged in the automotive sector which produces machinery for Isuzu products as well as several other car parts. The warehouse is a very vital place for every company, the optimal warehouse layout will support the company's production process in meeting production targets because makes it easy to get things. The potential for tools changes can not be avoided and can occur at any time, the search process for the old tools will increase maintenance time so that it is feared that the target wil not be met. This means that the layout of the tools shed must be made optimal so that when engine maintenance occurs the search process for the tools does not take much time. ABC Classification is a method for grouping based on 3 types: fast, medium, and slow. The results of this research are the layout of tools on a shelf based on $\mathrm{ABC}$ classification and $5 \mathrm{~S}$ principles. The layout of tools storage that has been arranged can facilitate the search for tools for workers so as to shorten the search time for tools so that the maintenance process can run effectively and efficiently. This is more effective because previously the arrangement of tools in the warehouse is irregular so that searching for tools takes a long time.
\end{abstract}

Keywords: Warehouse, Layout, ABC Classification

\section{Pendahuluan}

PT. Mesin Isuzu Indonesia adalah sebuah industri manufaktur yang bergerak dibidang otomotif yang memproduksi mesin-mesin untuk produk Isuzu serta beberapa part mobil lainya. Bahan baku yang akan di proses di PT.Mesin Isuzu Indonesia di datangkan langsung dari Izuzu Japan. PT. Mesin Isuzu Indonesia memproduksi beberapa produk antara lain : Engine, Cylinder Body, Cylinder Head, Camshaft, Transmision, 2 $\mathrm{Hub}$ dan Holder. PT. Mesin Isuzu Indonesia memiliki 3 line assembly dan 7 line machining. Penelitian kali ini berfokus pada line CYB machining.

Proses machining yaitu proses akhir setelah part mobil dicetak. Proses machining terdiri dari : drilling, boring, milling, dan turning (bubut). Proses ini bertujuan untuk menghaluskan permukaan, memberi lubang dan merapikan partpart yang telah dicetak. Pada proses machining dibutuhkan tools (mata pahat) untuk memproses part. Tools memiliki peran yang sangat signifikan, namun kalau tools memiliki kerusakan harus segera diganti dengan yang baru. Pada PT. Mesin Isuzu Indonesia proses pergantian tools memakan waktu yang cukup lama, karena gudang tools yang dimiliki kurang begitu tertata sehingga menyebabkan proses pencarian tools lama, karena proses pencarian tools lama produksi pun delay sehingga produktivitas dapat menurun. Maka dari itu penataan gudang khususnya tools harus diperbaiki supaya dapat menyingkat waktu maintenance dan produktivitas dapat meningkat.

Dalam melakukan produksinya salah satu faktor terpentingnya adalah gudang. Gudang adalah suatu tempat penyimpanan untuk semua barang-barang hasil produksi maupun penjualan. Fungsinya sebagai tempat penyimpanan memiliki peranan yang sangat vital. Oleh sebab itu diperlukan adanya pengaturan yang tepat dan cepat dalam penggunaan ruang gudang (Heldy Juliana et. al, 2016)

Tools merupakan salah satu unsur utama dalam proses produksi perusahaan yang menggunakan mesin CNC. Potensi terjadinya maintenance karena rusaknya tools tidak dapat dihindarkan. Proses maintenance akan berjalan lama apabila proses perbaikan lama, selain itu ada faktor lain yaitu proses pencarian spare part atau tools yang akan digunakan. Proses maintenance yang lama akan mengakibatkan proses produksi berhenti lama, sehingga akan menimbulkan tidak tercapainya target produksi. Berikut adalah data waktu maintenance pada line CYB tahun 2019 sampai dengan bulan juli. 
Tabel 1. Rekap Maintenance Line $C Y B$ Tahun 2019

\begin{tabular}{|c|c|c|c|c|c|c|c|c|c|c|c|}
\hline TOTAL & & MEC & & ElC & & Tool & & Mis Opr & & Others & \\
\hline Minutes & Times & Minutes & Times & Minutes & Times & Minutes & Times & Minutes & Times & Minutes & Times \\
\hline 3906 & 108 & 1319 & 36 & 472 & 29 & 650 & 6 & 285 & 5 & 0 & 0 \\
\hline
\end{tabular}

Sumber : Data Maintenance PT. Mesin Isuzu Indonesia

Dapat dilihat pada Tabel 1 bahwa waktu maintenance karena kerusakan tools menempati urutan kedua berdasarkan waktu maintenancenya. Hal ini berarti tools merupakan hal yang paling berpengaruh pada lamanya waktu maintenance khususnya pada line CYB.

Saat ini PT.Mesin Isuzu Indonesia tata letak pada gudang toolsnya belum diklasifikasikan berdasarkan tools yang sering digunakan. Letak tools pada gudang hanya diletakan pada tempat yang kosong saja. Karena banyaknya jenis tools dengan penataan yang kurang baik akan menimbulkan proses pencarian yang lama. Oleh karena itu pada penelitian kali ini akan mencari tata letak yang optimal sehingga dapat meminimalkan waktu pencarian.

\section{Landasan Teori}

\subsection{Gudang}

Gudang adalah bagian dari sistem logistik perusahaan yang menyimpan berbagai jenis barang baik bahan baku, komponen atau part, barang setengah jadi, maupun barang jadi pada dan antara titik sumber dan titik pengunaan serta menyajikan informasi kepada manajemen mengenai status, kondisi, dan perpindahan dari item yang disimpan (Sahara \& Bakthiar ,2016).

Gudang dapat memiliki aktivitas yang berbeda sesuai dengan spesifikasi produk yang disimpan. Banyak klasifikasi jenis gudang, seperti raw material storage yang berfungsi untuk menyimpan bahan baku pada suatu sistem produksi, working in process storage yang berfunsgi menyimpan material yang masih membutuhkan proses lanjutan atau setengah jadi, dan finishing goods storage gudang ini berfungsi untuk menyimpan barang yang sudah selesai melewati produksi hingga tahap akhir dan siap untuk distribusikan ke konsumen. Klasifikasi tersebut juga tergantung persyaratan pelanggan, dan tingkat layanan yang ditawarkan. Kompleksitas kegiatan gudang tergantung terutama pada: (i) jumlah dan jenis barang yang akan ditangani; (ii) jumlah beban kerja harian yang harus dilakukan; dan (iii) jumlah, sifat, dan variasi proses yang diperlukan untuk dipenuhi. (Kusrini.E. et. al. 2018)

\subsection{Klasifikasi $\mathrm{ABC}$}

Pengklasifikasian item logistik ini bertujuan untuk membedakan item logistik yang sangat penting, penting, dan tidak terlalu penting Analisis $\mathrm{ABC}$ digunakan untuk mengklasifikasikan barang kedalam kategori A, B,C. Kategori A merupakan kategori barang dimana memiliki jumlah yang sedikit sekitar $20 \%$ dari jumlah keseluruhan barang namun memiliki nilai sekitar $70 \%$ dari total. Pada kategori B, memiliki jumlah $30 \%$ dari jumlah keseluruhan barang didalam gudang dengan nilai mencapai $20 \%$ dari keseluruhan nilai persediaan. Untuk kategori C, memiliki jumlah 50\% dari total persediaan didalam gudang, dengan kontribusi nilai yang rendah yaitu sekitar $10 \%$ dari total nilai persediaan yang ada didalam gudang perusahaan (Ivan Gustin A, 2017).

\subsection{Prinsip 5S}

5S dalam bahasa Indonesia disebut juga sebagai 5R (Ringkas, Rapi, Resik, Rawat, Rajin). Salah satu metode yang kerap kali digunakan untuk mengoptimalkan proses penyimpanan warehouse adalah metode 5S, yaitu Seiri, Seiton, Seiso, Seiketsu, dan Shitsuke (Pramudian K.N 7 Susanto, 2019). Dengan metode 5S, diharapkan suatu warehouse dapat memiliki suatu kerja standar dengan kualitas terbaik, Misalnya dibuatkan standar visual dalam bentuk papan pengingat $5 \mathrm{~S}$ didalam gudang yang bertujuan untuk mengingatkan dan membiasakan pekerja untuk mengaplikasikan konsep 5S, selain itu juga dapat dilakukan dengan menetapkan standar pencarian tools sehingga pekerja dapat lebih efisien dalam proses pencarian tools. Metode $5 \mathrm{~S}$ juga diharapkan menjadi kebiasaan dan kesadaran para pekerja dalam melakukan pekerjaanya. Seiri berarti ringkas, seiton berarti rapi, seiso berarti bersih, seiketsu berarti rawat, dan shitsuke berarti rajin. Konsep 5S diharapkan dapat menyelesaikan hambatan-hambatan yang terjadi di area kerja seperti barang yang tersedia dalam jumlah besar, kesulitan dalam menemukan barang yang dicari, kerusakan fasilitas secara mendadak karena tak terpelihara dan kotor, prosedur kerja yang kurang jelas, dll. Semua hambatan di atas dapat mengakibatkan lingungan kerja menjadi tidak teratur dan kotor, tingginya potensi terjadi kecelakaan, menurunnya semangat kerja karyawan, menurunnya produktivitas karyawan, menurunnya kepercayaan customer. 


\section{Metode Penelitian}

Dalam melakukan penelitian ini ada beberapa tahap yang dilalui berikut adalah tahapan-tahapan penelitian yang dilalui :

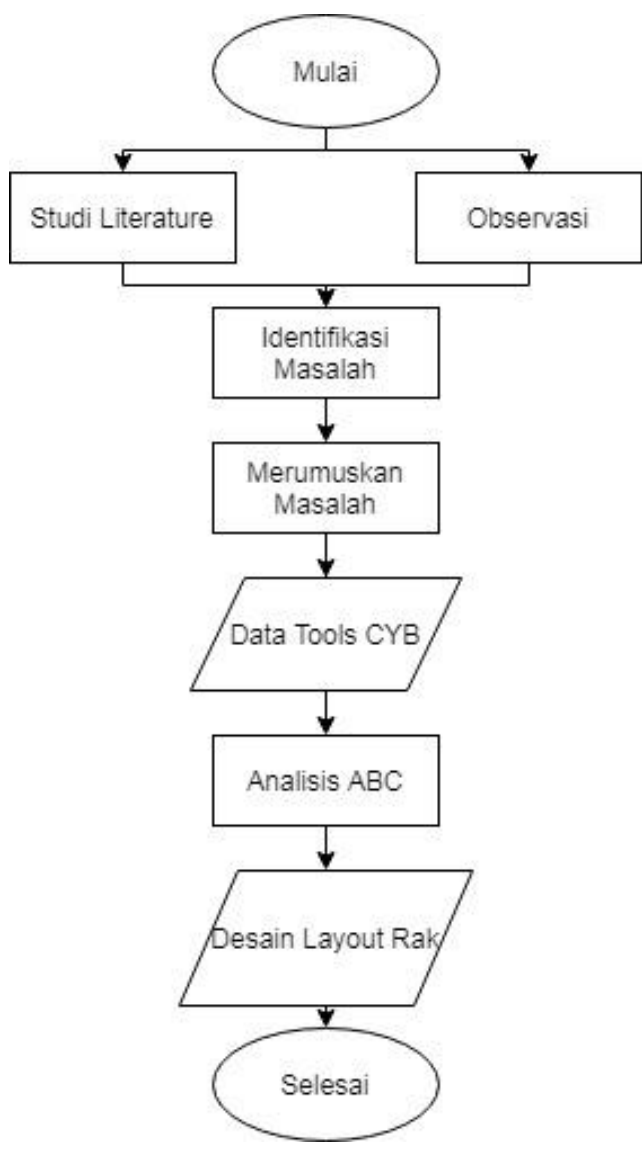

Gambar 1. Flowchart Penelitian Sumber : Langkah Penelitian

Pertama, observasi lapangan dilakukan untuk melihat secara langsung penggantian tools di PT. Mesin Isuzu Indonesia. Pada observasi lapangan dilakukan untuk mendapatkan penyebab masalah pencarian lama dengan cara wawancara untuk mengumpulkan informasi. Tahap studi literature dilakukan bersamaan dengan observasi, pada tahap ini penulis mencari metode yang cocok untuk menyeleseikan permasalahan yang ada pada gudang tools. Tahap identifikasi masalah dilakukan untuk menemukan masalah-masalah yang ada dan kaitannya dengan gudang tools. Setelah dilakukan identifikasi terhadap masalah kemudian dilakukan perumusan masalah yang bertujuan untuk mengetahui arah dari penelitian ini.

Tahap identifikasi masalah dilakukan untuk menemukan masalah-masalah yang ada dan kaitannya dengan gudang tools. Setelah dilakukan identifikasi terhadap masalah kemudian dilakukan perumusan masalah yang bertujuan untuk mengetahui arah dari penelitian ini.

Tahap pengambilan data, data yang didapat dari berbagai sumber diantaranya : wawancara dengan petugas gudang tools, wawancara dengan manager maintenance, dan wawancara dengan pekerja bagian produksi. Pada tahap ini didapatkan data tools yang digunakan untuk line CYB beserta dengan keterangan usia masingmasing tools.

Tahap analisis data, pada tahap ini dilakukan klasifikasi terhadap data yang telah didapat pada tahap pengumpulan data yaitu tools berdasarkan usia pakainya. Data-data tersebut diurutkan mulai dari usia pakai yang terkecil, kemudian diklasifikasikan menjadi 3 kelas yaitu kelas A (fast moving) sebanyak 20\% dari total item, kelas B (medium moving) sebanyak 30\% dari total item, dan kelas C (slow moving) sebanyak 50\% dari total item. Klasifikasi kelas A memiliki nilai sekitar 70\%, kelas B dengan nilai sekitar 20\% dan kelas C dengan kontribusi nilai $10 \%$ dari keseluruhan. (Ivan Gustin A, 2017). Setelah diklasifikasikan kemudian dilakukan penataan tools pada rak disesuaikan dengan klasifikasi $\mathrm{ABC}$ tersebut yakni untuk barang dengan usia pakai sedikit akan diletakan ditempat yang mudah dijangkau, dengan harapan pencarian akan lebih cepat.

\section{Hasil dan Pembahasan}

Tabel 2. Sample Tools Kategori A, B dan C

\begin{tabular}{ccc}
\hline Kode Tool & Total Life & Kategori \\
\hline IT-1001 & 625 & $\mathrm{~A}$ \\
TPGN 090208 & 750 & $\mathrm{~A}$ \\
SPHX 1205ZCELGP & 800 & $\mathrm{~A}$ \\
XTPGW 110304ILT- & & \\
P & 900 & $\mathrm{~A}$ \\
IM-1030-10 & 10000 & $\mathrm{~A}$ \\
ID-1021 & 10500 & $\mathrm{~B}$ \\
ID-1102 & 11000 & $\mathrm{~B}$ \\
ID-1097 & 15000 & $\mathrm{~B}$ \\
ID-1101 & 15000 & $\mathrm{~B}$ \\
ID-1045 & 16000 & $\mathrm{~B}$ \\
IM-1031 & 42000 & $\mathrm{~B}$ \\
IR-1004 & 42000 & $\mathrm{~B}$ \\
IR-1005 & 42000 & $\mathrm{C}$ \\
IR-1006 & 42000 & $\mathrm{C}$ \\
ID-1028 & 44000 & $\mathrm{C}$ \\
ID-1029 & 44000 & $\mathrm{C}$
\end{tabular}




\begin{tabular}{ccc} 
ID-1011 & 45000 & $C$ \\
ID-1046 & 45000 & $C$ \\
ID-1099 & 50000 & $C$ \\
IM-1023 & 50000 & $C$ \\
IM-1024 & 50000 & $C$ \\
IM-1068 & 50400 & $C$ \\
ID-1019 & 54000 & $C$ \\
\hline
\end{tabular}

Sumber : Pengolahan Data

Berdasarkan tabel 2 cutting tools yang ada pada line CYB ada 176 jenis. Kemudian diklasifikasikan menjadi 3 kategori yaitu A, B, dan C. Kategori A terdiri dari $20 \%$ item yaitu sebanyak 35 jenis, kategori B terdiri atas $30 \%$ item yaitu sebanyak 53 jenis, dan kategori $\mathrm{C}$ terdiri atas $50 \%$ item yaitusebanyak 88 jenis. Sebelum diklasifikasikan menjadi 3 kategori cutting tools tersebut diurutkan mulai dari life time terkecil ke yang terbesar berikut adalah perhitungan untuk klasifikasi $\mathrm{ABC}$ tersebut :

$$
\begin{aligned}
& \text { Kelas A }=20 \% \text { X } 176=35,2 \approx 35 \\
& \text { Kelas B }=30 \% \text { X } 176=52,8 \approx 53 \\
& \text { Kelas C }=50 \% \text { X } 176=88
\end{aligned}
$$

Selanjutnya setelah dilakukan klasifikasi tools ditata pada rak seperti gambar berikut ini :

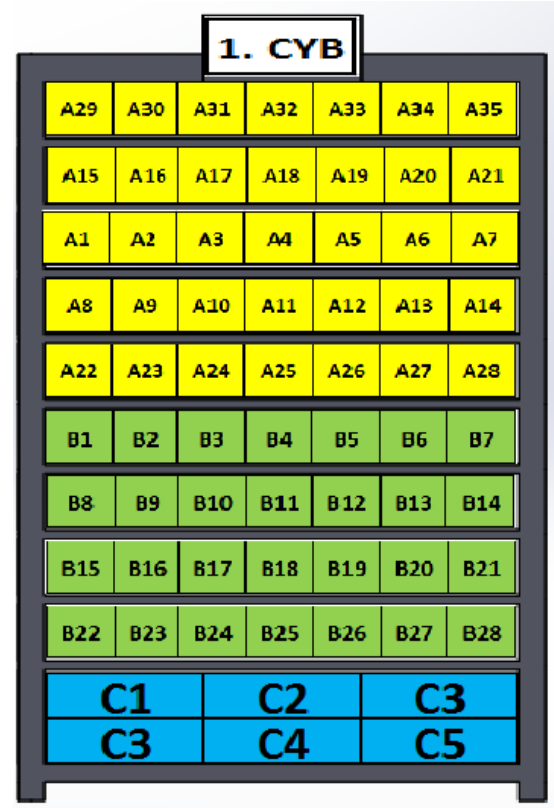

Gambar 2. Penempaatan cutting tools pada rak 1 Sumber : Pengolahan Data
Setelah dilakukan perbaikan dengan cara penataan tools seperti pada gambar 2 sampai gambar 6 pekerja dapat dengan mudah menemukan tools yang mereka inginkan sehingga metode ini diharapkan dapat mereduksi waktu maintenance yang cukup memakan waktu. Klasifikasi persediaan termasuk juga sparepart sangat diperlukan untuk menghindari mesin yang tidak beroprasi sehingga produktifitas menurun (Hudori M. 2017). Ketika waktu maintenance dapat dikurangi maka produksipun akan lebih lancar sehingga produktivitas pabrik dapat meningkat . Tidak hanya penting klasifikasi persediaan pada inventori sparepart, namun juga penting dalam pengawasan persediaan barang jadi, untuk mencegah keluarnya barang dalam kondisi yang tidak baik (Riani \& Bayu. 2016). Dari hasil klasifikasi ABC juga dapat terlihat persediaan sparepart mana saja yang perlu perhatian ketat (Hidayat.D.F. at al 2019). Dari hasil klasifikasi dapat dilihat bahwa sparepart atau tools pada klasifikasi A menjadi yang perlu diberi perhatian ketat karena memiliki pergerakan yang cepat (Fast moving).

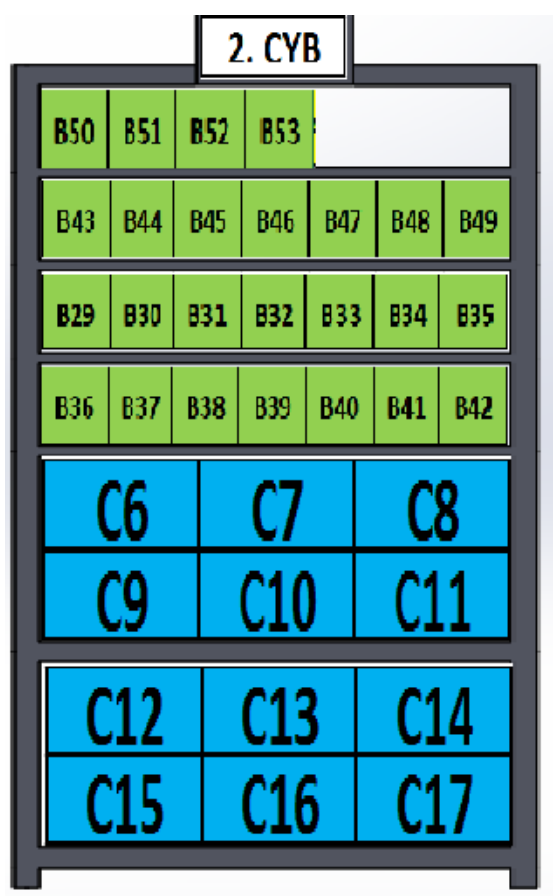

Gambar 3. Penempatan cutting tools rak 2 Sumber : Pengolahan Data 


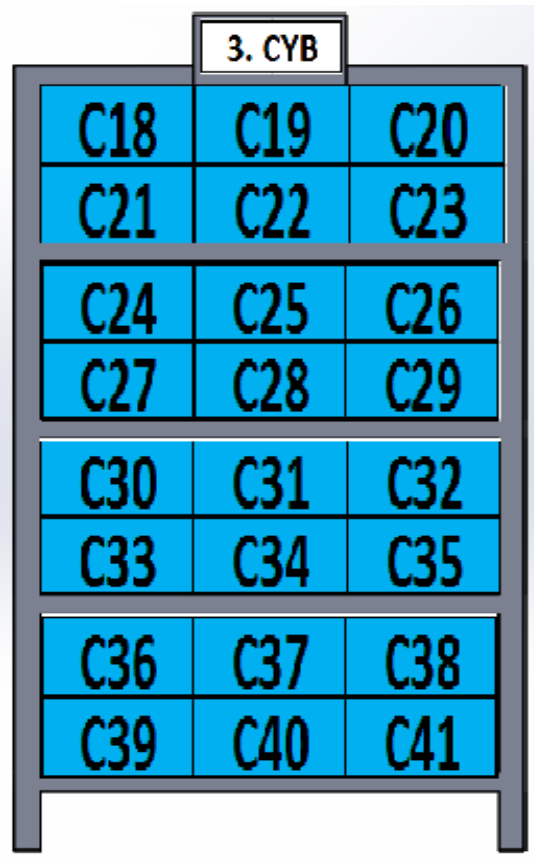

Gambar 4. Penempatan cutting tools pada rak 3 Sumber : Pengolahan Data

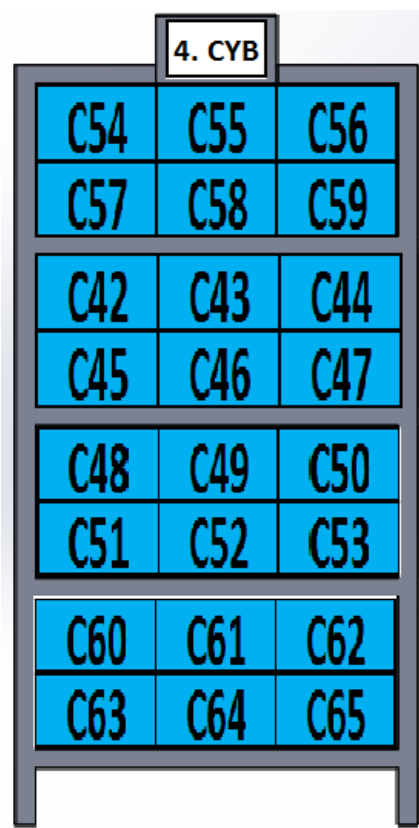

Gambar 5. Penempatan cutting tools pada rak 4 Sumber : Pengolahan Data

Pada Rak 3 sampai dengan rak 5 diisi dengan 70 jenis tool kategori C. Untuk raknya menggunakan tipe 3 yang dapat dilihat pada gambar 4, 5 dan 6 yang memiliki space untuk menempatkan tools besar pada tiap barisnya. Pada rak 5 masih tersisa 1 slot dikarenakan kategori $\mathrm{C}$ telah tertampung semua pada rak 1 sampai dengan rak 5 .

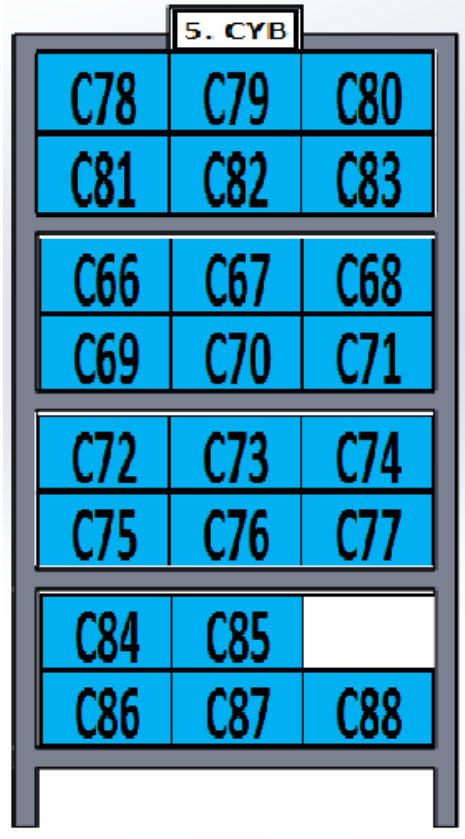

Gambar 6. Penempatan cutting tools pada rak 5 Sumber : Pengolahan Data

Barang dengan kode $\mathrm{C}$ berwarna biru adalah barang yang memiliki frekuensi pergerakan lambat, barang dengan kode B berwarna hijau adalah barang yang memiliki frekuensi penggunaan sedang, dan untuk barang dengan kode A berwarna kuning adalah barang yang memiliki frekuensi penggunaan sangat cepat atau sering.

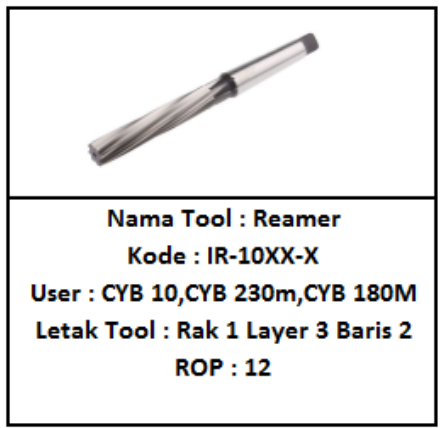

Gambar 7. Saran Pemberian Label untuk tiap wadah cutting tools Sumber : Saran Penulis

Gambar 7 merupakan saran untuk pelabelan pada wadah tools penerapan Kanban sehingga memudahkan pekerja ketika melakukan pencarian tools saat dibutuhkan. Penambahan spek dan gambar pada bagian wadah tools dapat mempercepat pencarian, karena apabila pekerja tidak mengetahui kode tools pekerja dapat melihat pada gambar yang ada pada wadah sehingga pekerja tidak perlu membuka wadah satu-persatu. Metode ini cukup efektif karena 
dengan hanya melihat gambar pada bagian depan wadah yang telah ditempel Kanban pekerja dapat tau apakah tools yang sedang dicari apakah sama dengan yang ada didalam wadah tersebut.

5S (Seiri, Seiton, Seiso, Seiketsu, Shitsuke) merupakan salah satu upaya pengorganisasian area kerja yang dilakukan dengan cara mengidentifikasi dan meletakkan alat yang benar benar diperlukan, menjaga kebersihan dan kerapihan area dan alat kerja dan mempertahankan ketertiban, agar tercipta area kerja yang bersih, efisien dan aman untuk meningkatkan produktivitas (Anthony, et.al, 2016). Berikut adalah detail Prinsip 5S yang perlu diterapkan :

1. Seiri (Ringkas)

Hal pertama yang harus dilakukan adalah menentukan barang-barang yang diperlukan dan yang tidak diperlukan untuk saat ini. Tujuan dari perancangan seiri ini adalah mengeluarkan barang-barang yang tidak diperlukan. Kondisi sebelumnya pada gudang tools masih banyak spare part mesin (mesin yang sudah tidak dipakai) masih disimpan, dengan adanya usulan ini diharapkan spare part yang tidak dipakai disingkirkan dari gudang tools. Selain itu juga perlu dilakukan inspeksi bulanan untuk mengecek tools atau spare part mana saja yang masih dipakai, untuk yang tidak terpakai dapat segera disingkirkan dari gudang.

2. Seiton (Rapi)

Inti dari perancangan seiton adalah alat-alat kerja dan barang jadi atau produk harus memiliki satu lokasi penyimpanan yang tetap. Tujuan perancangan adalah untuk mempermudah dalam pencarian barang, mengambil dan mengembalikan alat yang dibutuhkan. Kondisi sebelumnya pada gudang masih ada pekerja yang mencari ataupun mengembalikan tools tidak pada tempatnya lagi sehingga ketika akan mencari tools yang dibutuhkan tidak pada tempatnya. Rancangan ini dilakukan untuk mengurangi waktu pencarian dan menciptakan tata letak gudang yang lebih rapi.

3. Seiso (Resik)

Tugas dan kebersihan bukan hanya dilaksanakan bagian kebersihan saja narnun menjadi tugas dan tanggung jawab bersama di area gudang. Tujuan dari resik, membuat tempat kerja menjadi bersih dan nyaman bagi pekerja yang sedang melaksakan tugasnya. Kondisi sebelumnya pada gudang cukup bersih sehingga untuk usulannya cukup dijaga kekonsistenan kebersihan gudangnya.

4. Seiketsu (Rawat)

Inti dasar dari perancangan seiketsu adalah bagaimana memelihara area kerja selalu dalam kondisi rapi dan bersih. Salah satu cara yang dapat dilakukan dalam implementasi seiketsu di area gudang adalah merancang aktivitas inspeksi terhadap implementasi 5S.

5. Shisuke (Rajin)

Prinsip utama dari rajin adalah $5 \mathrm{~S}$ sebagai budaya kerja dalam aktivitas seharihari. Implementasi $5 \mathrm{~S}$ sebenamya sama dengan mengubah kebiasaan setiap orang. Jalan atau tidak implementasi $5 \mathrm{~S}$ tergantung dari kemauan setiap orang untuk mengubah kebiasaan yang mereka lakukan selama ini. Pada kondisi saat ini pekerja yang mengambil sesuatu di gudang tools masih kurang peduli sehingga harus selalu diingatkan atau diberi tahu dengan cara memasang papan berisikan pengingat $5 \mathrm{~S}$. Selain pemberian papan pengingat $5 \mathrm{~S}$ untuk menerapkan poin ini juga perlu dilakukan inspeksi setiap akhir shift untuk mengecek apakah tools ada pada tempat yang semestinya.

\section{Kesimpulan}

Berdasarkan penelitian dapat disimpulkan sebagai berikut :

1. Dengan penerapan metode $\mathrm{ABC}$ pada penataan tools diharapkan dapat mempercepat proses pencarian tools. Berdasarkan klasifikasi ABC tools terbagi menjadi tiga kelas yaitu : Kelas A (fast moving) sebanyak 35 jenis, Kelas B (medium moving) sebanyak 53 jenis, dan kelas C (slow moving) sebanyak 88 jenis tool dan membutuhkan 5 rak.

2. Usulan perbaikan yang diberikan adalah untuk menerapkan $5 \mathrm{~S}$ yang berkelanjutan dan konsisten. Kondisi Gudang tools sebelumnya yang belum maksimal dan konsisten dalam penerapan $5 \mathrm{~S}$, usulan perbaikan yang diberikan diharapkan dapat meningkatkan produktifitas dan mengurangi waste, walapun memerlukan adaptasi yang berkelanjutan bagi para operator. Dengan tujuan aktivitas tersebut khususnya di gudang tools PT. Mesin Isuzu Indonesia dapat berjalan secara efektif, efisien dan berkelanjutan. 


\section{Daftar Referensi}

Anthony, J., Vinodh, S. and Gijo, E. U. (2016) Lean Six Sigma for Small and Medium Sized Enterprises Boca Raton : CRC Press

Heldy, Julian, Naniek Utami H. 2016. PENINGKATAN KAPASITAS GUDANG DENGAN PERANCANGAN LAYOUT MENGGUNAKAN METODE CLASSBASED STORAGE. Semarang. Jurnal Teknik Industri, Vol. XI, No. 2

Hidayat. D.F. Ossa. S. \& Akhmad.F. (2019). Analisis Pengendalian Persediaan Gudang Barang Jadi Dengan Analisa ABC Pada Perusahaan Cat PT.PR. Journal Industrial Manufacturing. Vol.4. No.1. Pp 63-66.

Hudori, M. (2017). Penentukan Kelompok Persediaan Sparepart Pada Industri Baja Menggunakan Analisis Klasifikasi ABC. Journal Citra Widya Edukasi. Vol IX. No 2. Agustus 2017.

Ivan Gustin. A. (2017). Perancangan Tata Letak Gudang pada UD Diamond Jaya di Surabaya. Surabaya. Jurnal Ilmiah Mahasiswa Universitas Surabaya. Vol.6 No.2

Kusrini, E, Citra, I, Galuh, M, Anisa, N, Alex, K, Sadiq, A, \& Indro,P. (2018). Warehousing performance improvement using Frazelle Model and per group benchmarking: A case study in retail warehouse in Yogyakarta and Central Java. MATEC Web of Conferences 154. 2018.

Pramudian K Nadiya, dan Susanto Novie. (2019) Analisis Penerapan Metode 5S pada Warehouse Fast Moving PT. Indonesia Power UBP Mrica Kabupaten Banjarnegara. Semarang. Media Ilmiah Teknik Industri

Riani, L. P., \& Bayu, W. (2016). Analisis ABC dalam pengendalian persediaan Sapre Part Jenis Oli Speda Motor di Bengkel Piramida Motor Tulungagung. Jurnal Nusamba Vol.1 No.1. 2016.

Sahara, S. N., \& Bakhtiar, A. (2016). Perbaikan Tata Letak Penempatan Material Di Area Gudang Penyimpanan Material Berdasarkan Clas Based Storage Policy (Studi Kasus: Gudang PT. TIMATEX SALATIGA). Jurnal Teknik Industri Universitas Diponegoro. Vol.5, No 4. 